\title{
Role of StdA in adhesion of Salmonella enterica serovar Enteritidis phage type 8 to host intestinal epithelial cells
}

\author{
Daniel C Shippy, Nicholas M Eakley, Dareen M Mikheil and Amin A Fadl
}

\begin{abstract}
Background: Salmonella is often implicated in foodborne outbreaks, and is a major public health concern in the United States and throughout the world. Salmonella enterica serovar Enteritidis (SE) infection in humans is often associated with the consumption of contaminated poultry products. Adhesion to epithelial cells in the intestinal mucosa is a major pathogenic mechanism of Salmonella in poultry. Transposon mutagenesis identified stdA as a potential adhesion mutant of SE. Therefore, we hypothesize StdA plays a significant role in adhesion of SE to the intestinal mucosa of poultry.

Methods and results: To test our hypothesis, we created a mutant of SE in which stdA was deleted. Growth and motility were assayed along with the in vitro and in vivo adhesion ability of the $\triangle s t d A$ when compared to the wild-type SE strain. Our data showed a significant decrease in motility in $\triangle s t d A$ when compared to the wild-type and complemented strain. A decrease in adhesion to intestinal epithelial cells as well as in the small intestine and cecum of poultry was observed in $\Delta s t d A$. Furthermore, the lack of adhesion correlated to a defect in invasion as shown by a cell culture model using intestinal epithelial cells and bacterial recovery from the livers and spleens of chickens.
\end{abstract}

Conclusions: These studies suggest StdA is a major contributor to the adhesion of Salmonella to the intestinal mucosa of poultry.

Keywords: Salmonella, Adhesion, StdA, Poultry

\section{Background}

Salmonella is a significant foodborne bacterium associated with enteric disease outbreaks in humans due to the consumption of contaminated food. Salmonella serovars, like Salmonella enterica serovar Enteritidis (SE), are the leading cause of death among the major foodborne pathogens [1]. SE phage type (PT) 8 is one of the most common PTs associated with egg-associated outbreaks in the United States while SE PT4 is the most common in Europe [2,3]. Therefore, the identification and evaluation of Salmonella virulence factors could help develop new ways to control salmonellosis in the farm to fork food processing cycle.

A hallmark of Salmonella virulence is its ability to invade host intestinal epithelial cells [4]. This is a multi-step process mediated by a type 3 secretion system (T3SS)

\footnotetext{
* Correspondence: fadl@wisc.edu

Department of Animal Sciences, University of Wisconsin-Madison, 1675 Observatory Drive, Madison, WI 53706, USA
}

encoded within Salmonella pathogenicity island-1 (SPI-1) $[5,6]$. The first step in the invasion process is the adhesion of Salmonella to the host intestinal epithelial cells. Several pathogenic factors have been implicated in adhesion to host cells. The best characterized are the fimbrial adhesins which include type 1, plasmid-encoded, long polar, and thin aggregative fimbriae [7-10]. A further study has suggested that the T3SS itself can mediate host cell adhesion by showing that SipB, SipC, and SipD are required for the intimate association of Salmonella with mammalian cells [11]. Inhibition of Salmonella adhesion at the initial stages of infection is potentially the most effective strategy for controlling salmonellosis in production animals which could result in reduced contamination of our food supply [12].

In this study, we identified $s t d A$ as an adhesion mutant of SE by transposon mutagenesis. The $s t d A$ deletion mu$\operatorname{tant}(\Delta s t d A)$ displayed a normal growth profile when compared to the wild-type (WT) SE PT8 and complemented 
strains. A motility assay showed a significant decrease in motility for $\Delta s t d A$. Adhesion and invasion assays showed $\Delta s t d A$ was deficient in cell culture models of Salmonella adhesion and invasion. Furthermore, $\Delta s t d A$ was deficient in a poultry model of Salmonella adhesion and invasion with the systemic infection deficiency most likely due to the decreased adhesion. Taken together, these data indicated a major role for StdA in the adhesion ability of SE host cells.

\section{Results}

\section{Analysis of $\Delta s t d A$}

The chromosomal $s t d A$ gene was replaced by a kanamycin resistance gene $\left(\mathrm{Kn}^{\mathrm{R}}\right)$ cassette using the lambda Red recombination system. Deletion of stdA from the chromosome of SE was confirmed by PCR analysis. The primer set $K_{3} / K_{5}$ was used to amplify the $\mathrm{Kn}^{\mathrm{R}}$ cassette, while the primer set $\mathrm{F}_{2} / \mathrm{R}_{2}$ was used to confirm the absence of $s t d A$. To ensure correct orientation of the $\mathrm{Kn}^{\mathrm{R}}$ cassette, the primer set $\mathrm{F}_{3} / \mathrm{K}_{5}$ was used to amplify the upstream $s t d A$ flanking sequence along with the $\mathrm{Kn}^{\mathrm{R}}$ cassette, while $\mathrm{R}_{3} /$ $\mathrm{K}_{3}$ was used to amplify the downstream stdA flanking sequence along with the $\mathrm{Kn}^{\mathrm{R}}$ cassette. Overall, these results indicated that a stdA deletion mutant of SE PT8 was successfully created.

\section{StdA does not affect Salmonella growth}

Growth curve analysis was conducted for the WT, $\Delta s t d A$, and complemented strains in order to determine the relevance of StdA on Salmonella growth. All three strains displayed nearly identical growth profiles suggesting StdA does not play a significant role in SE growth (Figure 1).

\section{$\Delta s t d A$ is deficient in motility}

A motility assay was conducted to see if StdA has a role in SE motility. Measurement of the motility plates displayed a

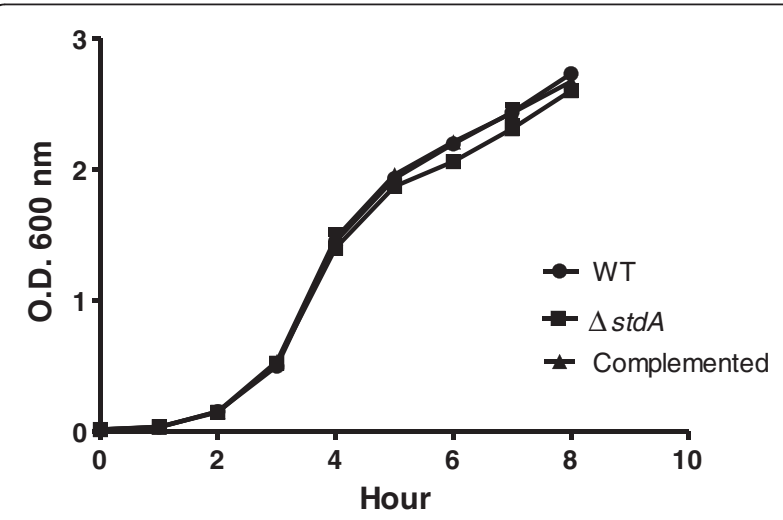

Figure 1 Growth curves of the WT, $\Delta s t d A$, and complemented strains. The strains were grown in $L B$ and the optical densities at $600 \mathrm{~nm}$ were measured each hour. The graph is representative of two independent experiments. significantly reduced migration from the inoculation site to the periphery of the plate for $\Delta s t d A(19 \mathrm{~mm})$ when compared to the WT $(68 \mathrm{~mm})$ and complemented $(64 \mathrm{~mm})$ strains (Figure 2).

\section{$\Delta s t d A$ is attenuated in adhesion and invasion in vitro}

Inoculation of intestinal epithelial cells displayed a significant decrease in adhesion ability in $\Delta s t d A$ (3.6 logs) when compared to the WT (6.0 logs) and complemented strains (5.9 logs) (Figure 3A). Furthermore, $\Delta s t d A$ displayed the same significant decrease in the ability to invade T84 intestinal epithelial cells (Figure 3B). The adhesion and invasive ability of $\triangle s t d A$ was restored after complementation, suggesting StdA plays a role in adhesion and invasion of intestinal epithelial cells by SE. It is logical to conclude that the invasion defect seen in $\Delta s t d A$ is an effect of the adhesion deficiency.

\section{Deletion of $s t d A$ attenuates SE adhesion and invasion in chickens}

A chicken model of infection was used to determine the role of StdA in the adhesion ability of SE to the intestinal mucosa of chickens. At 16 hours post-infection, the bacterial counts of WT SE from the small intestine were 7.1 logs compared to $0.75 \operatorname{logs}$ for $\Delta s t d A$. At day 7 postinfection, bacterial counts from the small intestine were $4.1 \operatorname{logs}$ for the WT with no bacteria recovered for $\Delta s t d A$ (Figure 4A). For the cecum, bacterial counts from chickens infected with the WT SE strain were 8.7 and 9.1 logs at the 16 hour and day 7 time points, respectively compared to 5.8 and $6.1 \operatorname{logs}$ for $\Delta s t d A$ (Figure $4 \mathrm{~B}$ ). These data suggest StdA plays a role in the adhesion ability of SE to the intestinal mucosa of chickens.

We also assayed the bacterial counts from the livers and spleens to see if the adhesion deficiency displayed by $\triangle s t d A$ affected systemic infection in chickens. At the 16 hour time point, there was no bacteria recovered from the livers and spleens of chickens infected with the WT and $\Delta s t d A$ strains. At the day 7 time point, bacterial counts in the liver were 7.2 and $4.5 \operatorname{logs}$ comparing the WT and $\triangle s t d A$, respectively (Figure 5A). Furthermore, bacterial counts in the spleen were 7.8 and 5.0 logs comparing the WT and $\triangle s t d A$, respectively (Figure $5 \mathrm{~B}$ ). These data suggest that the adhesion deficiency displayed by $\triangle s t d A$ contributes to an overall reduction in systemic infection by SE in poultry.

\section{Discussion}

In this study, an adhesion mutant of SE was created and characterized. Transposon mutagenesis identified StdA as a potential adhesion mutant of SE. A $\Delta s t d A$ strain of SE was created using the lambda Red recombination system, and was deficient in adhesion in both cell culture and chicken models of infection. Additionally, this adhesion 


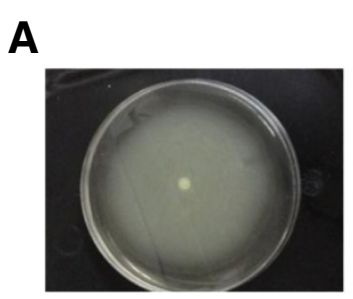

WT

B

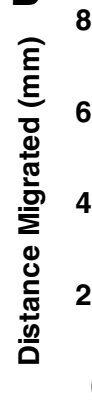

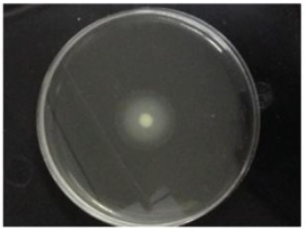

$\Delta s t d A$

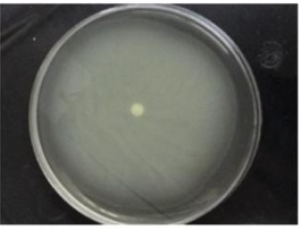

Complemented

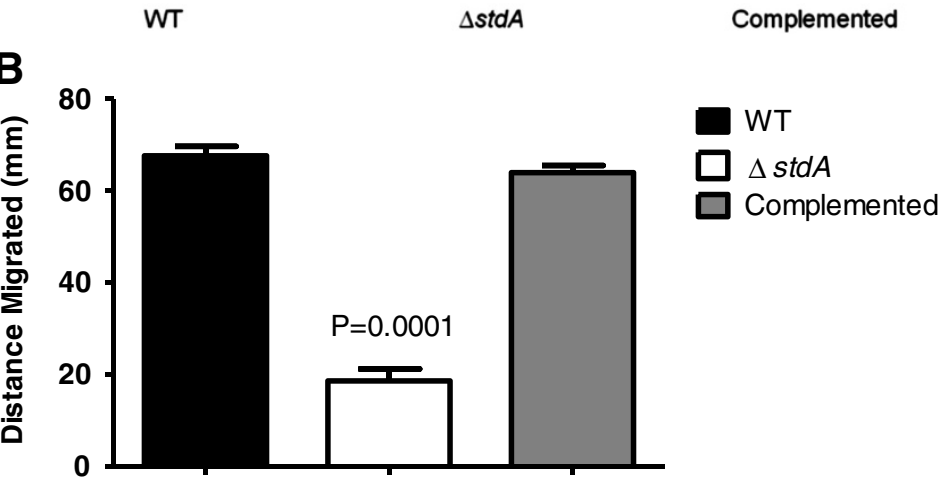

Figure 2 Motility assay of the WT, $\Delta s t d A$, and complemented strains. Bacteria were spotted onto soft agar, and migration of the bacteria was measured from the inoculation point to the periphery of the plate. (A) Images showing the migration of each SE strain. (B) Graph displaying the migration of each SE strain. The actual $P$ values are given displaying a statistically significant difference between $\triangle s t d A$ and the WT strain.

defect lead to a deficiency in invasion of T84 intestinal epithelial cells, and decreased overall systemic infection ability in a poultry model as evidenced by reduced bacterial counts in the livers and spleens of chickens inoculated with $\Delta s t d A$. These data indicated that StdA plays a significant

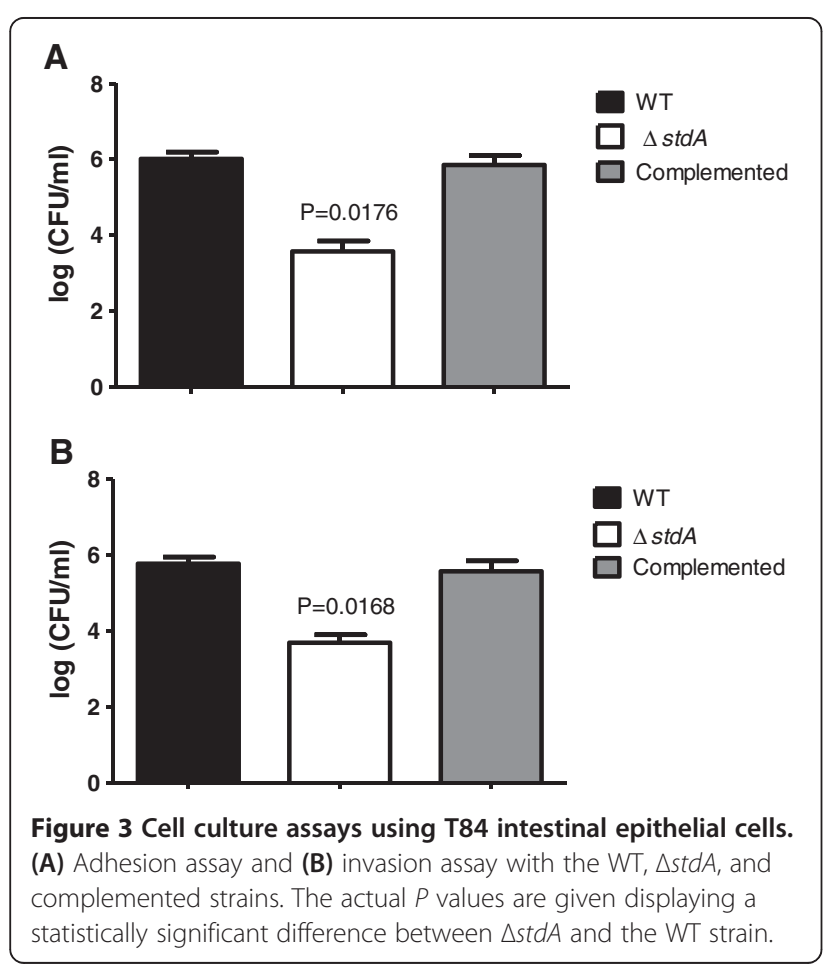

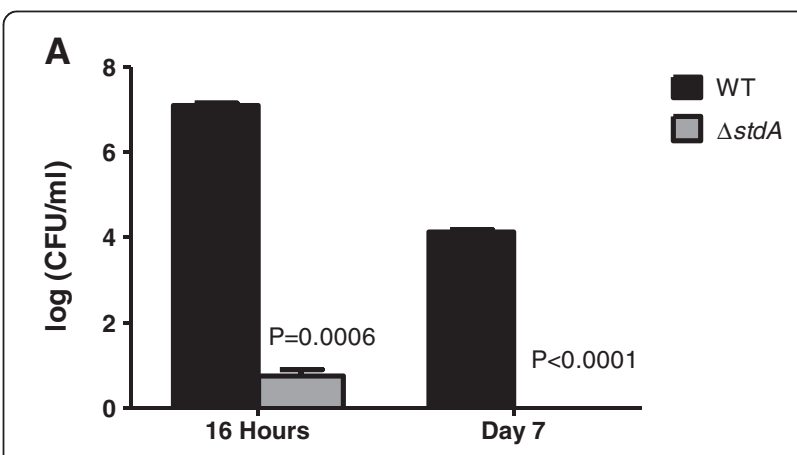

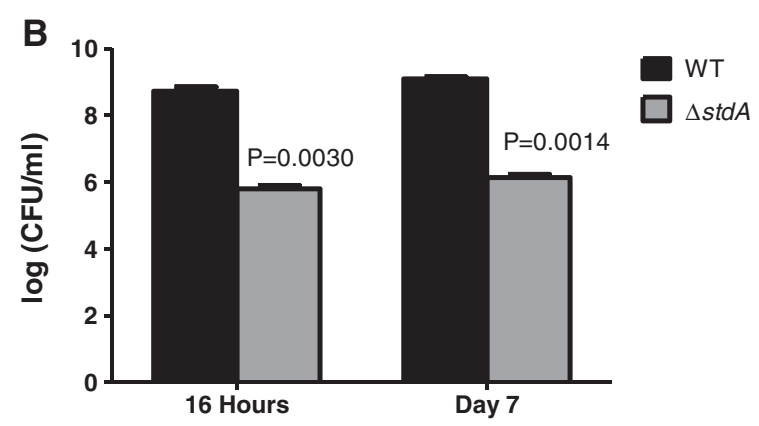

Figure 4 Determination of adhesion ability in poultry. Bacterial counts in (A) small intestine and (B) cecum of chickens inoculated by oral crop gavage with $1 \times 10^{7} \mathrm{CFU}$ of WT and $\triangle s t d A$. The actual $P$ values are given displaying a statistically significant difference between $\triangle$ stdA and the WT strain. 


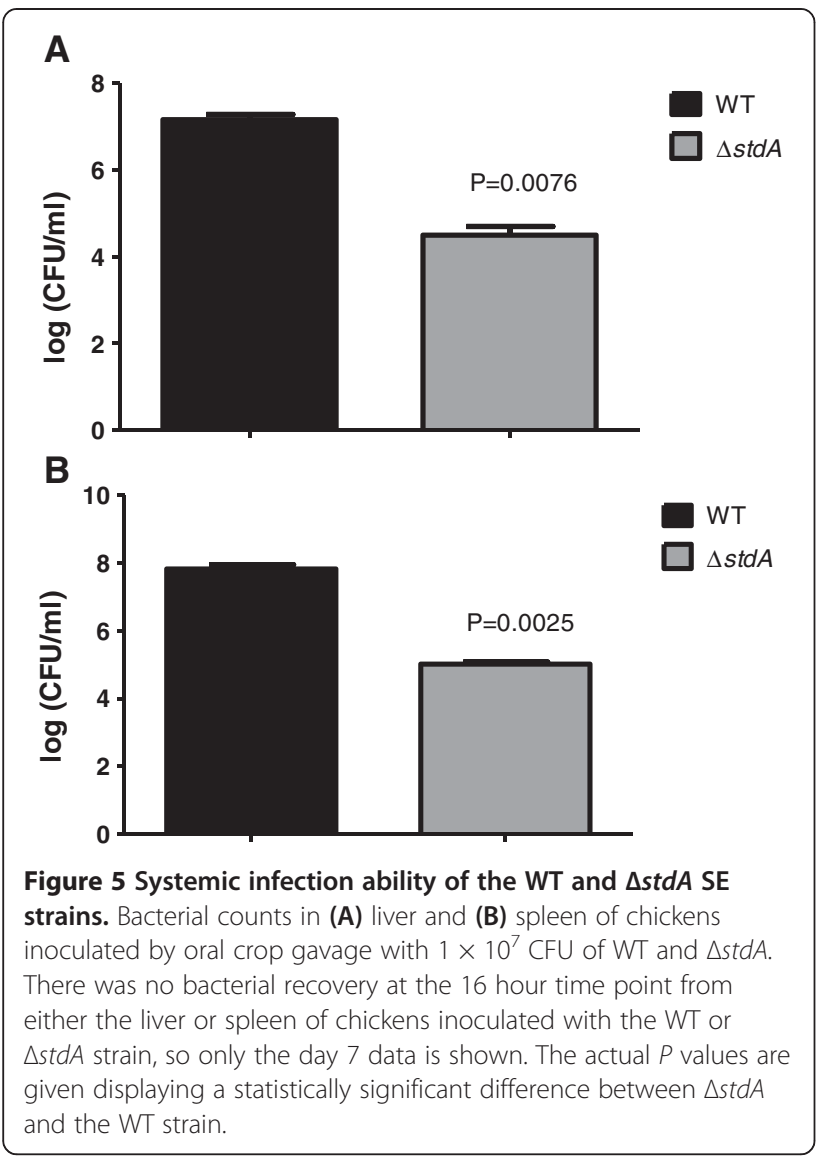

role in the adhesion ability of SE to the intestinal mucosa of poultry.

StdA is a $19-k D a$ fimbrial protein that is part of the std operon which was originally identified during sequence analysis of the Salmonella enterica serovar Typhi CT18 strain [13]. It was later found to be in other serovars of Salmonella including Salmonella enterica serovar Typhimurium (STM) [14-17]. In STM, the Std fimbriae play a role in Salmonella adhesion to specific sections of the intestinal mucosa as evidenced by std operon deletion mutants having reduced intestinal persistence in mice $[18,19]$. This correlates to the data observed in our study, where deletion of $s t d A$ significantly alerted the adhesion ability of SE in the intestinal mucosa of poultry.

The synthesis of Std fimbriae is tightly regulated, but the mechanisms involved in std expression are unclear. In the study by Balbontin et al., gene expression profiling of a dam mutant of STM demonstrated that transcription of the std operon is repressed by Dam methylation [20]. In another study, Jakomin et al. showed that uncontrolled expression of Std fimbriae contributes to the attenuated virulence observed in dam mutants of STM [21]. They also described a regulatory role for SeqA as a repressor of the std operon and HdfR as an activator of std expression whose activity may be antagonized by SeqA [21]. Further regulatory evidence was displayed in the study by Chessa et al. which identified RosE as a novel transcriptional regulator of Std fimbrial expression in STM [18]. Further investigation into the regulation of $s t d A$, and how it affects Salmonella adhesion to the intestinal mucosa of poultry will be conducted in our laboratory.

An interesting observation in our study is that $\Delta s t d A$ displayed a significant decrease in motility. Motility is hypothesized to be a pathogenic mechanism because it promotes contact with the surface of epithelial cells by allowing the bacterium to penetrate the thick mucus layer covering the intestinal mucosa [22,23]. Some studies suggest a role for flagella in bacterial adhesion to host tissue $[24,25]$. The study by Erdem et al. suggests a role for $\mathrm{FliC}$ in $E$. coli adhesion to bovine intestinal tissue while the study by Olsen et al. suggests a role for FliC in Salmonella binding to intestinal epithelial cells [24,25]. Further studies will be needed to determine how StdA affects Salmonella motility and if this motility reduction contributes to the adhesion and invasion defect seen in $\Delta s t d A$.

Additional studies will also be needed in order to gauge the level of attenuation of the $\Delta s t d A$ SE strain in chickens. Depending on the outcome of these studies, further studies could be conducted to determine if $\Delta s t d A$ is a good candidate for use in a live-attenuated poultry vaccine.

\section{Conclusions}

Transposon mutagenesis identified StdA as a potential adhesion mutant of SE. A $\Delta s t d A$ strain of SE was created using the lambda Red recombination system, and was deficient in adhesion both in vitro and in vivo. Additionally, this lack of adhesion lead to a deficiency in invasion of T84 intestinal epithelial cells, and decreased overall systemic infection ability in a poultry model as evidenced by reduced bacterial counts in the livers and spleens of chickens inoculated with $\Delta s t d A$. Overall, our data suggest StdA plays a role in the adhesion ability of Salmonella to the intestinal mucosa of chickens, and could be an important factor in the early stages of Salmonella infection in poultry.

\section{Methods}

\section{Bacterial strains, plasmids, and cell lines}

The WT SE PT8 E2627 strain was isolated from an egg-associated outbreak in the United States [26]. All Salmonella strains were grown in either Luria-Bertani (LB) medium or on Salmonella-Shigella (SS) plates. Additionally, all homogenates from the in vivo experiments were incubated in Selenite-F broth (BD, Sparks, MD). Nalidixic acid $(100 \mu \mathrm{g} / \mathrm{ml})$, kanamycin $(50 \mu \mathrm{g} / \mathrm{ml})$, tetracycline $(15 \mu \mathrm{g} / \mathrm{ml})$, and ampicillin $(100 \mu \mathrm{g} / \mathrm{ml})$ were added to the media as necessary. A complete list of the bacterial strains and plasmids used in this study is shown in Table 1. T84 intestinal epithelial cells were obtained from the American Type Culture Collection (ATCC, Manassas, VA), and were subsequently 
Table 1 Strains and plasmids used in this study

\begin{tabular}{|c|c|c|}
\hline Strain or plasmid & Relevant characteristics & Source or reference \\
\hline Serovar Enteritidis phage type 8 E2627 & Isolated from an egg-associated outbreak in the United States & [26] \\
\hline$\Delta s t d A$ & Mutant of serovar Enteritidis in which stdA was deleted using lambda Red; $\mathrm{Kn}^{\mathrm{r}}$ & This study \\
\hline$\triangle s t d A / p B R s t d A$ & $\Delta s t d A$ complemented with a copy of the $s t d A$ gene via pBR322; $\mathrm{Kn}^{r}, T c^{r}$ & This study \\
\hline \multicolumn{3}{|l|}{ E. coli } \\
\hline $\mathrm{DH} 5 \mathrm{a}$ & Used for recombinant DNA methods & Lab stock \\
\hline \multicolumn{3}{|l|}{ Plasmids } \\
\hline pKD46 & lambda Red recombinase genes; $A p^{r}$ & Lab stock \\
\hline pBR322 & $A p^{r} T C^{r}$ & Lab stock \\
\hline pKD4 & $\mathrm{Kn}^{\mathrm{r}}$ gene cassette & Lab stock \\
\hline pBRstdA & stdA gene cloned into pBR322 at the Scal site & This study \\
\hline
\end{tabular}

grown and maintained in Dulbecco's Modified Eagle Medium: Nutrient Mixture F12 (DMEM/F12) medium supplemented with $10 \%$ fetal bovine serum (FBS), and incubated at $37^{\circ} \mathrm{C}$ with $5 \% \mathrm{CO}_{2}$.

\section{Construction of the mutant and complemented strains}

The transposon binding screening which identified $\Delta s t d A$ as a potential binding mutant of SE is described in [27]. The $\Delta s t d A$ strain was created using the lambda Red recombination system as previously described [28]. Briefly, WT SE PT8 was transformed with the pKD46 plasmid that carries the lambda Red recombinase genes [28]. Arabinoseinduced WT SE carrying pKD46 was cultured and used to generate the electrocompetent cells. The kanamycin resistance gene $\left(\mathrm{Kn}^{\mathrm{R}}\right)$ was PCR amplified from the pKD4 plasmid using primer set LF/LR [28]. The $5^{\prime}$-end of the LF primer carries 40 extra bases homologous to the upstream Salmonella stdA gene while the $5^{\prime}$-end of the LR primer carries 40 bases homologous to the downstream stdA flanking sequence. The PCR product was purified and electroporated into the WT-pKD46 electrocompetent cells. After transformation, colonies growing on LB plates supplemented with kanamycin were selected as candidates for $s t d A$ mutants of SE. To confirm deletion of the $s t d A$ gene, the selected mutants were subjected to PCR analysis using primer sets $K_{3} / K_{5}$ and $F_{2} / R_{2}$ to show the presence of the $\mathrm{Kn}^{\mathrm{R}}$ and the absence of $s t d A$.

The stdA complemented strain was constructed by amplifying a DNA fragment containing $s t d A$ from the WT SE strain using primer set $F_{3} / R_{3}$. The DNA fragment was blunt-ended using a PCR polishing kit (Stratagene, Santa Clara, CA) and ligated into the blunt-ended Scal restriction enzyme digested pBR322 vector. The recombinant plasmid was transformed into the $s t d A$ mutant by electroporation. A complete list of the primers used in this study is shown in Table 2.

\section{Growth analysis}

Growth curve profiles were constructed in order to determine the significance of StdA on SE growth. An equal number of cells from the WT, $\Delta s t d A$, and complemented strains were inoculated in LB and grown at $37^{\circ} \mathrm{C}$. The optical densities at $600 \mathrm{~nm}$ were recorded each hour.

\section{Motility assay}

The motility assay was performed as previously described [29]. Briefly, soft agar (LB medium with $0.3 \%$ agar) was

Table 2 Sequence and purpose of primers used in this study

\begin{tabular}{|c|c|}
\hline Primer name and sequence & Purpose \\
\hline LF:5'-AAAGGACATATTATCTATGCGTAATAAAATAATACTTGCCTGTGTAGGCTGGAGCTGCTT-3' & $\begin{array}{l}\text { Forward primer for amplification of the } \mathrm{Kn}^{\mathrm{R}} \text { gene cassette and } \\
\text { upstream stdA flanking sequence }\end{array}$ \\
\hline LR:5'-CCGTGGACGGCTTCTCCCTGTCGTTATTTACCGCGTGAAACATATGAATATCCTCCTTAG-3' & $\begin{array}{l}\text { Reverse primer for amplification of the } \mathrm{Kn}^{\mathrm{R}} \text { gene cassette and } \\
\text { downstream stdA flanking sequence }\end{array}$ \\
\hline$F_{2}: 5^{\prime}$-CATCACCAACTCACCCTGTG-3' & Forward primer for amplification of the stdA gene \\
\hline $\mathrm{R}_{2}: 5^{\prime}-\mathrm{CTGAGGTATCTGCTGTGCCA-3^{ \prime }}$ & Reverse primer for amplification of the stdA gene \\
\hline$F_{3}: 5^{\prime}-A T T C A T A T G G T G C T T C G T T T A A C A C C-3^{\prime}$ & Forward primer for amplification of stdA for complementation \\
\hline$R_{3}: 5^{\prime}-A G A C T C G A G T C A C A G G T A T T T C A G G-3^{\prime}$ & Reverse primer for amplification of stdA for complementation \\
\hline$K_{3}:$ 5'-AAAGCCACGTTGTGTCTA-3' & Forward primer for amplification of the $\mathrm{Kn}^{\mathrm{r}}$ gene cassette \\
\hline $\mathrm{K}_{5}: 5^{\prime}-$ CGCTGAGGTCTGCCTCGT-3' & Reverse primer for amplification of the $\mathrm{Kn}^{\mathrm{r}}$ gene cassette \\
\hline
\end{tabular}


used to characterize the motility phenotype of the WT, $\Delta s t d A$, and complemented SE strains. Overnight cultures of each Salmonella strain were adjusted to the same optical density. Equal numbers of CFU $\left(1 \times 10^{6}\right)$ were spotted onto $0.3 \% \mathrm{LB}$ agar. The plates were incubated at $37^{\circ} \mathrm{C}$, and motility was determined by examining the migration of the bacteria from the center of the inoculation point to the periphery of the plate.

\section{Adhesion assay}

The adhesion assay was performed as previously described [30]. Briefly, $5 \times 10^{5}$ T84 intestinal epithelial cells were seeded per well in a 24-well tissue culture plate and incubated overnight at $37^{\circ} \mathrm{C}$ with $5 \% \mathrm{CO}_{2}$. The following day, cells were infected with the WT, $\Delta s t d A$, and complemented strains at a multiplicity of infection (MOI) of 10:1. The plate was briefly centrifuged, and incubated for 30 minutes at $37^{\circ} \mathrm{C}$ with $5 \% \mathrm{CO}_{2}$. Unbound bacteria were aspirated; the wells washed six times with phosphate buffered saline (PBS), and the cells were lysed with $0.1 \%$ Triton X-100 (TX-100). Dilutions of the cell lysates were plated on SS agar for enumeration of bacteria.

\section{Invasion assay}

The invasion assay was performed as previously described [30]. Briefly, $5 \times 10^{5}$ T84 intestinal epithelial cells were seeded per well in a 24-well plate and incubated overnight at $37^{\circ} \mathrm{C}$ with $5 \% \mathrm{CO}_{2}$. The cells were infected with the WT, $\Delta s t d A$, and complemented strains at an MOI of 10:1, and briefly centrifuged so that the bacterial cells would be in direct contact with the T84 cells. After incubation for 30 minutes at $37^{\circ} \mathrm{C}$ with $5 \% \mathrm{CO}_{2}$, the cells were washed three times with PBS and incubated for an additional 45 minutes with gentamicin-containing medium $(100 \mu \mathrm{g} / \mathrm{ml})$ to kill extracellular bacteria. Following incubation, the gentamicin-containing medium was removed, the wells were washed six times with PBS, and the cells were lysed with $0.1 \%$ TX-100. The lysate was diluted and plated out on SS agar plates for colonyforming unit (CFU) determination.

\section{Chicken experiments}

One-week-old specific-pathogen-free (SPF) White Leghorn chickens were purchased from Charles River (Wilmington, MA). Groups of 11 birds were infected by oral crop gavage with $1 \times 10^{7} \mathrm{CFU}$ of the WT or $\Delta s t d A$ SE strains. Another group of birds $(n=4)$ was inoculated by oral crop gavage with $100 \mu \mathrm{l}$ sterile PBS to serve as a control. At 16 hours and 7 days post-infection, 5 birds from each group were euthanized using $\mathrm{CO}_{2}$. Portions of the liver, spleen, small intestine, and cecum were removed from each bird. The individual organs were pooled and 1 gram was homogenized in $10 \mathrm{ml}$ PBS. One $\mathrm{ml}$ from each homogenate was incubated in $10 \mathrm{ml}$ Selenite-F broth at $36^{\circ} \mathrm{C}$ for 18 hours.
Direct plating of the organ homogenates was done in parallel with plating from the enrichment cultures [31-34]. Enumeration of bacteria was performed by serial dilution from the Selenite-F broth and plating on SS agar.

\section{Statistical analysis}

Wherever appropriate, the data were analyzed using GraphPad Prism 5 software (GraphPad Software, San Diego, CA) and a Student's $t$ test. $P$ values of $\leq 0.05$ were considered significant. Unless otherwise stated, experiments were repeated two times and data were expressed as arithmetic means with standard deviations.

\section{Competing interests}

The authors declare that they have no competing interests.

\section{Authors' contributions}

DS carried out the in vivo and in vitro experimental work, performed the statistical analysis, and drafted the manuscript. NE performed the transposon screening and identified the adhesion mutants. DM created the stdA mutant strain. AF designed and coordinated the study, and edited the manuscript. All authors read and approved the final manuscript.

\section{Acknowledgements}

We thank Dr. Charles Kaspar, University of Wisconsin-Madison, for providing the WT SE PT8 isolate. This work was supported by a grant from the University of Wisconsin-Madison Graduate School.

Received: 26 November 2013 Accepted: 21 December 2013

Published: 24 December 2013

\section{References}

1. Scallan E, Hoekstra RM, Angulo FJ, Tauxe RV, Widdowson MA, Roy SL, Jones JL, Griffin PM: Foodborne illness acquired in the United States-major pathogens. Emerg Infect Dis 2011, 17(1):7-15.

2. Hickman-Brenner FW, Stubbs AD, Farmer JJ 3rd: Phage typing of Salmonella enteritidis in the United States. J Clin Microbiol 1991, 29(12):2817-2823.

3. Nygard K, de Jong B, Guerin PJ, Andersson Y, Olsson A, Giesecke J: Emergence of new Salmonella Enteritidis phage types in Europe? Surveillance of infections in returning travellers. BMC Med 2004, 2:32.

4. Patel JC, Galan JE: Manipulation of the host actin cytoskeleton by Salmonella-all in the name of entry. Curr Opin Microbiol 2005, 8(1):10-15.

5. Galan JE: Molecular genetic bases of Salmonella entry into host cells. Mol Microbiol 1996, 20(2):263-271.

6. Schlumberger MC, Hardt WD: Salmonella type III secretion effectors: pulling the host cell's strings. Curr Opin Microbiol 2006, 9(1):46-54.

7. Baumler AJ, Heffron F: Identification and sequence analysis of IpfABCDE, a putative fimbrial operon of Salmonella typhimurium. J Bacterio/ 1995, 177(8):2087-2097.

8. Clegg S, Purcell BK, Pruckler J: Characterization of genes encoding type 1 fimbriae of Klebsiella pneumoniae, Salmonella typhimurium, and Serratia marcescens. Infect Immun 1987, 55(2):281-287.

9. Friedrich MJ, Kinsey NE, Vila J, Kadner RJ: Nucleotide sequence of a $13.9 \mathrm{~kb}$ segment of the $90 \mathrm{~kb}$ virulence plasmid of Salmonella typhimurium: the presence of fimbrial biosynthetic genes. Mol Microbiol 1993, 8(3):543-558

10. Grund $S$, Weber $A: A$ new type of fimbriae on Salmonella typhimurium. Zentralb/ Veterinarmed B 1988, 35(10):779-782.

11. Lara-Tejero M, Galan JE: Salmonella enterica serovar typhimurium pathogenicity island 1-encoded type III secretion system translocases mediate intimate attachment to nonphagocytic cells. Infect Immun 2009, 77(7):2635-2642

12. Wizemann TM, Adamou JE, Langermann S: Adhesins as targets for vaccine development. Emerg Infect Dis 1999, 5(3):395-403.

13. Townsend SM, Kramer NE, Edwards R, Baker S, Hamlin N, Simmonds M, Stevens K, Maloy S, Parkhill J, Dougan G, et al: Salmonella enterica serovar Typhi possesses a unique repertoire of fimbrial gene sequences. Infect Immun 2001, 69(5):2894-2901. 
14. Anjum MF, Marooney C, Fookes M, Baker S, Dougan G, Ivens A, Woodward MJ: Identification of core and variable components of the Salmonella enterica subspecies I genome by microarray. Infect Immun 2005, 73(12):7894-7905.

15. Chan K, Baker S, Kim CC, Detweiler CS, Dougan G, Falkow S: Genomic comparison of Salmonella enterica serovars and Salmonella bongori by use of an S. enterica serovar typhimurium DNA microarray. J Bacteriol 2003, 185(2):553-563.

16. Humphries AD, Raffatellu M, Winter S, Weening EH, Kingsley RA, Droleskey R, Zhang S, Figueiredo J, Khare S, Nunes J, et al: The use of flow cytometry to detect expression of subunits encoded by 11 Salmonella enterica serotype Typhimurium fimbrial operons. Mol Microbiol 2003, 48(5):1357-1376.

17. Porwollik S, Boyd EF, Choy C, Cheng P, Florea L, Proctor E, McClelland M: Characterization of Salmonella enterica subspecies I genovars by use of microarrays. J Bacterio/ 2004, 186(17):5883-5898.

18. Chessa D, Winter MG, Nuccio SP, Tukel C, Baumler AJ: RosE represses Std fimbrial expression in Salmonella enterica serotype Typhimurium. Mol Microbiol 2008, 68(3):573-587.

19. Weening EH, Barker JD, Laarakker MC, Humphries AD, Tsolis RM, Baumler AJ: The Salmonella enterica serotype Typhimurium Ipf, bcf, stb, stc, std, and sth fimbrial operons are required for intestinal persistence in mice. Infect Immun 2005, 73(6):3358-3366.

20. Balbontin R, Rowley G, Pucciarelli MG, Lopez-Garrido J, Wormstone Y, Lucchini S, Garcia-Del Portillo F, Hinton JC, Casadesus J: DNA adenine methylation regulates virulence gene expression in Salmonella enterica serovar Typhimurium. J Bacterio/ 2006, 188(23):8160-8168.

21. Jakomin M, Chessa D, Baumler AJ, Casadesus J: Regulation of the Salmonella enterica std fimbrial operon by DNA adenine methylation SeqA, and HdfR. J Bacteriol 2008, 190(22):7406-7413.

22. Jones BD, Ghori N, Falkow S: Salmonella typhimurium initiates murine infection by penetrating and destroying the specialized epithelial M cells of the Peyer's patches. J Exp Med 1994, 180(1):15-23.

23. Schmitt CK, Ikeda JS, Darnell SC, Watson PR, Bispham J, Wallis TS, Weinstein DL, Metcalf ES, O'Brien AD: Absence of all components of the flagellar export and synthesis machinery differentially alters virulence of Salmonella enterica serovar Typhimurium in models of typhoid fever, survival in macrophages, tissue culture invasiveness, and calf enterocolitis. Infect Immun 2001, 69(9):5619-5625.

24. Erdem AL, Avelino F, Xicohtencatl-Cortes J, Giron JA: Host protein binding and adhesive properties of $\mathrm{H} 6$ and $\mathrm{H} 7$ flagella of attaching and effacing Escherichia coli. J Bacteriol 2007, 189(20):7426-7435.

25. Olsen JE, Hoegh-Andersen KH, Casadesus J, Rosenkranzt J, Chadfield MS, Thomsen LE: The role of flagella and chemotaxis genes in host pathogen interaction of the host adapted Salmonella enterica serovar Dublin compared to the broad host range serovar S Typhimurium. BMC Microbiol 2013, 13:67.

26. Buchrieser C, Brosch R, Buchrieser O, Kristl A, Luchansky JB, Kaspar CW: Genomic analyses of Salmonella enteritidis phage type 4 strains from Austria and phage type 8 strains from the United States. Zentralb Bakteriol 1997, 285(3):379-388.

27. Shippy DC, Eakley NM, Mikheil DM, Fadl AA: Role of the flagellar basal-body protein, FlgC, in the binding of Salmonella enterica serovar Enteritidis to host cells. Curr Microbiol 2014. in press.

28. Datsenko KA, Wanner BL: One-step inactivation of chromosomal genes in Escherichia coli K-12 using PCR products. Proc Natl Acad Sci USA 2000, 97(12):6640-6645.

29. Yim L, Betancor L, Martinez A, Giossa G, Bryant C, Maskell D, Chabalgoity JA: Differential phenotypic diversity among epidemic-spanning Salmonella enterica serovar enteritidis isolates from humans or animals. Appl Environ Microbiol 2010, 76(20):6812-6820.

30. Shippy DC, Eakley NM, Bochsler PN, Chopra AK, Fadl AA: Biological and virulence characteristics of Salmonella enterica serovar Typhimurium following deletion of glucose-inhibited division (gidA) gene. Microb Pathog 2011, 50(6):303-313.

31. Fernandez F, Hinton M, Van Gils B: Dietary mannan-oligosaccharides and their effect on chicken caecal microflora in relation to Salmonella Enteritidis colonization. Avian Pathol 2002, 31(1):49-58.

32. Johnston CE, Hartley C, Salisbury AM, Wigley P: Immunological changes at point-of-lay increase susceptibility to Salmonella enterica Serovar enteritidis infection in vaccinated chickens. PLoS One 2012, 7(10):e48195.

33. Johny AK, Baskaran SA, Charles AS, Amalaradjou MA, Darre MJ, Khan MI, Hoagland TA, Schreiber DT, Donoghue AM, Donoghue DJ, et al:
Prophylactic supplementation of caprylic acid in feed reduces Salmonella enteritidis colonization in commercial broiler chicks. J Food Prot 2009, 72(4):722-727

34. Kollanoor-Johny A, Mattson T, Baskaran SA, Amalaradjou MA, Babapoor S, March B, Valipe S, Darre M, Hoagland T, Schreiber D, et al: Reduction of Salmonella enterica serovar enteritidis colonization in 20-day-old broiler chickens by the plant-derived compounds trans-cinnamaldehyde and eugenol. Appl Environ Microbiol 2012, 78(8):2981-2987.

doi:10.1186/1757-4749-5-43

Cite this article as: Shippy et al:: Role of StdA in adhesion of Salmonella enterica serovar Enteritidis phage type 8 to host intestinal epithelial cells. Gut Pathogens 2013 5:43.

\section{Submit your next manuscript to BioMed Central and take full advantage of:}

- Convenient online submission

- Thorough peer review

- No space constraints or color figure charges

- Immediate publication on acceptance

- Inclusion in PubMed, CAS, Scopus and Google Scholar

- Research which is freely available for redistribution
C Biomed Central 